\title{
COVID-19 and RAAS inhibitors: the controversy continues
}

\author{
Govindapala $D S^{1 *}$, Matthias $A \mathbf{T}^{2}$, Manilgama $S^{3}$, Wanigatunge $C^{4}$ \\ Journal of the Ceylon College of Physicians, 2020, 51, 43-47
}

\begin{abstract}
Since the beginning of the recent SARS-COVID pandemic, renin-angiotensin-aldosterone system inhibitors (RAASIs) have been in the center of controversy. The virus interacts with angiotensin converting enzyme 2 (ACE2) receptors in the lungs at the initial step of its entry in to the body. Theoretically, therapeutic use of RAASIs may aggravate the severity of lung damage by increasing ACE2 expression in the lung tissues.
\end{abstract}

Given the widespread use of angiotensin converting enzyme inhibitors and angiotensin receptor blockers among patients with high blood pressure and other non-communicable diseases in Sri Lanka, some guidance on the use of these drugs in patients with Corona virus Disease 2019 (COVID-19) is needed. At present there isn't any credible evidence to support the withdrawals from those who are on regular treatment with these drugs. We present the available data on the subject while awaiting the results of the observational studies that is being conducted with RAAls in patients with COVID-19.

Key words: RAAS inhibitors, ACEIs, ARB, ACE2, COVID-19

\section{Introduction}

Currently the world is at the grips of a rapidly evolving pandemic caused by SARS-CoV-2, a novel coronavirus with clinical presentation somewhat similar to that of severe acute respiratory syndrome (SARS) and Middle East respiratory syndrome (MERS). Since it was first reported in Wuhan, China at the end of
2019 as the cause of a cluster of pneumonia, there were more than 3090445 confirmed cases and 217 769 deaths worldwide as of $30^{\text {th }}$ April $2020^{1}$.

SARS-CoV-2 utilises the ACE2 receptors to gain entry to human lung tissues, similar to SARS-CoV ${ }^{2}$. Therefore, it is prudent to understand the inter-action between the virus and the ACE2 receptor. Most patients with cardiovascular disease qualify for treatment with angiotensin converting enzyme inhibitors (ACEIs) or angiotensin receptor blockers (ARBs) and Ferrario et al. (2005) has reported that both ACEls and ARBs could significantly increase the expression of cardiac ACE2 mRNA $^{3}$. Several Chinese studies have shown a high prevalence of cardiovascular disease among hospitalised COVID-19 patients with severe disease $^{4}$. Based on these, Sommerstein and Gräni (2020) hypothesized that angiotensin-converting enzyme inhibitors (ACEIs) may act as a potential risk factor for COVID-19 by up-regulating ACE2 ${ }^{5}$. Since then, series of articles have been published on this possible interaction.

ACEIs and ARBs are medicines widely used in the treatment of hypertension, heart failure, diabetes and coronary artery diseases. Mortality associated with COVID-19 is increased in those with these comorbid conditions and elderly ${ }^{6}$. The prevalence of non-communicable diseases in Sri Lanka is substantial ${ }^{7}$ and as such, a significant number of patients are also on regular, long term treatment with ACEIs/ARBs for coronary artery disease, hypertension and diabetes mellitus. Currently, there is a growing concern about the continued use of ACEIs/ARBs in those infected with or at risk of COVID-19 infection. Hence, we draw

\footnotetext{
${ }^{1}$ Faculty of Medicine, Sir John Kotelawala Defence University, ${ }^{2}$ Faculty of Medical Sciences, University of Sri Jayewardenepura,

${ }^{3}$ Teaching Hospital, Kandy, ${ }^{4}$ Faculty of Medical Sciences, University of Sri Jayewardenepura, Sri Lanka.
}

Correspondence: DSG, e-mail: dumithagovindapala@kdu.ac.Ik

http://orcid.org/0000-0001-6795-7913

Received 04 May 2020, accepted 16 May 2020.

This is an open-access article distributed under the terms of the Creative Commons Attribution License, which permits unrestricted use, distribution, and reproduction in any medium, provided the original author and source are credited. 
our focus on available data to analyse the relationship of SARS-CoV-2 and ACE2 receptors and the effects of COVID-19 on those treated with ACEIS/ARBs.

\section{SARS-CoV-2 and ACE 2 receptors}

The renin-angiotensin-aldosterone system (RAAS) is a classic endocrine system which plays a pivotal role in the development of hypertension and associated cardiovascular diseases ${ }^{8}$. Angiotensin II is the main active substrate of renin-angiotensin-aldosterone (RAA) pathway which by binding to type-1 receptors (ATR-1) causes a variety of effects, including vasoconstriction and vascular remodeling ${ }^{9}$.

ACE2 is a cellular transmembrane protein with an extra cellular receptor binding site ${ }^{10}$. It is the key counter regulatory enzyme of the RAAS which causes degradation of angiotensin II to angiotensin 1-7 (Ang 1-7 $)^{11}$. In addition, ACE2 directly hydrolyses the angiotensin I to angiotensin 1-9 (Ang 1-9) ${ }^{11}$. ACE2 is distributed in various organs of the human body, mainly in the epithelium of the airways, type II alveolar cells, enterocytes of the small intestine, endothelial cells of arteries and veins and brain ${ }^{10}$. The tissue distribution of ACE2 is organ specific and its expression is low in the lung. In normal human lung tissues, ACE2 expression in type I and II alveolar epithelial cells may get upregulated in certain clinical states ${ }^{10}$.

Corona viruses are a large family of enveloped single standard RNA viruses with potential to cause infection in broad range of vertebrates ${ }^{12}$. The viral genome encodes four major structural proteins and the spike (S) protein, a surface glycoprotein which facilitates the virus entry into host cells ${ }^{13}$. Sequential analysis has shown only $75 \%$ similarity between the $\mathrm{S}$ protein of SARS-CoV-2 and SARS-CoV ${ }^{14}$. However, the amino acid residues on the receptor binding motif (RBM) in the S protein were conserved between these two virus strains, suggesting that SARS-CoV-2 also use the same receptor to enter humans as SARS$\mathrm{CoV}^{15}$. The priming of $S$ protein by the host serine protease TMPRSS 2 is crucial for the virus to gain entry into the host and the subsequent spread within the host $^{2}$. The binding of virus S protein with the enzyme results in endocytosis of the virus and translocation of both virus and the enzyme into the endosomes ${ }^{16}$. New virus particles are produced inside the cell and viruses are released via exocytosis.

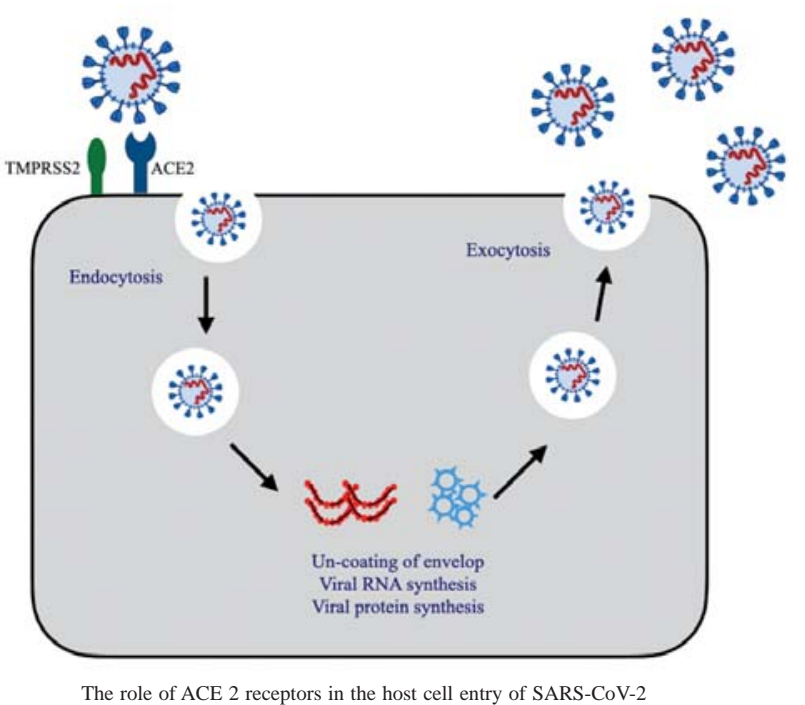

\section{Effects of ACEIs/ARBs on ACE2 receptors}

In-vivo animal studies show mixed findings with respect to the effect of ACEIs on ACE2 expression on various tissues. The effect of ARBs on ACE2 levels and its activity are inconsistent in experimental animal models where some studies have shown upregulation of ACE2 expression while others have shown no effect $t^{3,17,18}$. Treatment with olmesartan has shown to cause a concomitant rise in plasma angiotensin concentrations and ACE2 mRNA expression in the myocardium ${ }^{19}$. Continuous administration of lisinopril has a 5-fold rise of the cardiac ACE2 mRNA expression while a 3-fold rise was observed with losartan ${ }^{17}$.

Human studies regarding the effects of RAAS inhibition on ACE2 expression and its activity are limited. In one study, intravenous administration of ACEls did not affect the production of angiotensin 1-7 in patients with coronary artery disease ${ }^{20}$. Few studies on plasma ACE2 activity in patients with coronary artery disease, heart failure and atrial fibrillation have shown no difference in patients on RAAS inhibitors compared to control groups ${ }^{21,22}$. Despite the $42 \%$ structural homology between ACE 2 and ACE, their substrate specificity and enzymatic activity are quite different and therefore, the activity of ACE2 is not directly affected by the clinical use of ACEIs ${ }^{23}$.

These seemingly conflicting data indicates a lack of correlation between the degree of ACE2 expression on tissues and its activity. While it is known that the effects of ARB and ACEls therapy is mainly due to the 
ACE2 expression on cardiac tissues, the effects on lung specific ACE2 mRNA expression in humans is not yet fully understood ${ }^{24}$.

In contrast, another hypothesis argues that the RAAS inhibitors can be protective. It has shown that binding of corona virus to ACE2 can result in down regulation of ACE2 expression ${ }^{25}$. This can result in excessive production of angiotensin II due to the ACE/ ACE2 imbalance. Angiotensin II can increase pulmonary vascular permeability and lung damage. Hence, upregulation of ACE2 expression with long term treatment with ACE inhibitors and ARBS can theoretically mitigate the lung injury by two main mechanisms. First by degrading angiotensin II into angiotensin 1-7 and thereby reducing the angiotensin II mediated deleterious effects. Second by increasing production of angiotensin 1-7 which has been found to be protective in several lung injury models ${ }^{26}$.

A study by Liu et al. (2020) showed that serum angiotensin II levels in patients with COVID-19 pneumonia was significantly higher compared with healthy individuals and were linearly associated with viral load and lung injury ${ }^{27}$. It is therefore possible for those infected with SARS CoV-2 to have an increased risk of acute lung injury. Blocking the RAA system by ACEIs/ARBs and resultant increase in ACE2 might help to reduce these harmful effects ${ }^{25}$.

\section{Use of ACEI/ARBs in those with COVID-19}

The limited data available on the use of ACEIs/ ARBs in those with COVID-19, is conflicting. Analysis of data obtained via a symptom tracker app from a large but relatively young, community-based population of app users, has shown a modest increased risk of self-reported COVID-19 infection with classical symptoms in those taking $\mathrm{ACEls}^{28}$.

However, in a retrospective, multi-center study of adult patients with hypertension diagnosed with COVID-19, inpatient use of ACEI/ARB was associated with lower risk of all-cause mortality compared with ACEI/ARB non-users ${ }^{29}$. The authors therefore concluded that in-hospital use of ACEI/ARB is unlikely to be associated with an increased mortality risk. Another study from Wuhan, China that evaluated hypertensives hospitalized with COVID-19, observed no difference in disease severity or death rate in patients taking ACE inhibitors or ARBs and those not taking such medications ${ }^{30}$. A preliminary study from United Kingdom (not peer reviewed) also did not show any evidence for ACEIs increasing the short-term severity of COVID-19 disease, but showed a reduced risk of rapidly deteriorating severe disease ${ }^{31}$. As the sample sizes of all these studies were small, large scale studies are needed for more conclusive evidence.

These studies provide a modest reassurance that the use of ACE inhibitors or ARBs in hypertensive patients with COVID-19 does not increase the risk of clinical deterioration or death. This is encouraging as there is established benefit of RAAS inhibitors in protecting myocardium and kidneys and the potential for harm related to the withdrawal of RAAS inhibitors in patients in otherwise stable condition. The issue is further complicated as COVID-19 is severe in those with underlying cardiac disease and that COVID-19 is also associated with myocardial injury ${ }^{6,32}$.

\section{Conclusions}

The evidence for benefit and harm due to use of RAAS inhibitors in those with COVID-19 remains controversial at best. Limited studies conducted so far show that continuing RAAS inhibitors in those with COVID-19 is not associated with poor outcomes. In the absence of strong evidence, all published guidelines by the relevant professional associations worldwide, recommend against stopping RAASIs in those on regular therapy for clinical conditions for which proven benefit exists when infected with SARS-CoV- ${ }^{33}$.

\section{References}

1. Coronavirus Disease 2019 (COVID-19) Situation Report-101, WHO.; 2020. Accessed May 1, 2020. https://www. who.int/ emergencies/diseases/novel-coronavirus-2019/situationreports

2. Hoffmann M, Kleine-Weber H, Schroeder S, et al. SARSCoV-2 Cell Entry Depends on ACE2 and TMPRSS2 and Is Blocked by a Clinically Proven Protease Inhibitor. Cell 2020; 181(2): 271-80.e8. doi:10.1016/j.cell.2020.02.052

3. Ferrario CM, Jessup J, Chappell MC, et al. Effect of angiotensin-converting enzyme inhibition and angiotensin II receptor blockers on cardiac angiotensin-converting enzyme 2. Circulation 2005; 111(20): 2605-2610. doi:10.1161/ CIRCULATIONAHA.104.510461

4. Team TNCPERE, Team TNCPERE. The Epidemiological Characteristics of an Outbreak of 2019 Novel Coronavirus Diseases (COVID-19) China, 2020. China CDC Weekly 2020; 2(8): 113-22. doi:10.46234/CCDCW2020.032

5. Sommerstein R. Re: Preventing a covid-19 pandemic: ACE inhibitors as a potential risk factor for fatal Covid-19. The 
British Medical Journal. 2020; 368: m810. https:// www.bmj.com/content/368/bmj.m810/rr-2

6. Wu Z, McGoogan JM. Characteristics of and Important Lessons from the Coronavirus Disease 2019 (COVID-19) Outbreak in China: Summary of a Report of 72314 Cases from the Chinese Center for Disease Control and Prevention. Journal of the American Medical Association 2020; 323(13): 1239-42. doi:10.1001/jama.2020.2648

7. Status, Determinants and Interventions on Cardiovascular Disease \& Diabetes in Sri Lanka: ADesk Review of Research Ministry of Health, Nutrition and Indigenous Medicine.; 2019.

8. Chamsi-Pasha MAR, Shao Z, Tang WHW. Angiotensinconverting enzyme 2 as a therapeutic target for heart failure. Current Heart Failure Reports 2014; 11(1): 58-63. doi:10.1007/s11897-013-0178-0

9. Tikellis C, Thomas MC. Angiotensin-Converting Enzyme 2 (ACE2) Is a Key Modulator of the Renin Angiotensin System in Health and Disease. Volume 2012, Article ID 256294 https:/ /www.hindawi.com/journals/ijpep/2012/256294/.

10. Hamming I, Timens W, Bulthuis MLC, Lely AT, Navis GJ, van Goor $\mathrm{H}$. Tissue distribution of ACE2 protein, the functional receptor for SARS coronavirus. A first step in understanding SARS pathogenesis. Journal of Pathology 2004; 203(2): 631-37. doi:10.1002/path.1570

11. Vickers C, Hales P, Kaushik V, et al. Hydrolysis of biological peptides by human angiotensin-converting enzyme-related carboxypeptidase. Journal of Biological Chemistry 2002; 277(17): 14838-43. doi:10.1074/jbc.M200581200

12. Fehr AR, Perlman S. Coronaviruses: An overview of their replication and pathogenesis. In: Coronaviruses: Methods and Protocols. Springer New York; 2015: 1-23. doi:10.1007/ 978-1-4939-2438-7_ 1

13. Schoeman D, Fielding BC. Coronavirus envelope protein: Current knowledge. Virology Journal 2019; 16(1): 1-22. doi:10.1186/s12985-019-1182-0

14. Zhou P, Yang X Lou, Wang XG, et al. A pneumonia outbreak associated with a new coronavirus of probable bat origin. Nature 2020; 579(7798): 270-3. doi:10.1038/s41586-0202012-7

15. Wan Y, Shang J, Graham R, Baric RS, Li F. Receptor Recognition by the Novel Coronavirus from Wuhan: an Analysis Based on Decade-Long Structural Studies of SARS Coronavirus. Journal of Virology 2020; 94(7). doi:10.1128/ jvi.00127-20

16. Hofmann H, Pöhlmann S. Cellular entry of the SARS coronavirus. Trends in Microbiology 2004; 12(10): 46672. doi:10.1016/j.tim.2004.08.008

17. Sukumaran V, Veeraveedu PT, Gurusamy N, et al. Cardioprotective effects of telmisartan against heart failure in rats in-duced by experimental autoimmune myocarditis through the modulation of Angiotensin-Converting Enzyme2/Angiotensin 1-7/Mas Receptor axis. International Journal of Biological Sciences 2011; 7(7): 1077-92. doi:10.7150/ ijbs.7.1077

18. Burchill LJ, Velkoska E, Dean RG, Griggs K, Patel SK, Burrell LM. Combination renin-angiotensin system blockade and angiotensin-converting enzyme 2 in experimental myocardial infarction: Implications for future therapeutic directions. Clinical Science 2012; 123(11): 649-58. doi:10.1042/ CS20120162

19. Ishiyama $Y$, Gallagher PE, Averill DB, Tallant EA, Brosnihan $\mathrm{KB}$, Ferrario $\mathrm{CM}$. Upregulation of Angiotensin-Converting Enzyme 2 after Myocardial Infarction by Blockade of Angiotensin II Receptors. Hypertension 2004; 43(5): 970-6. doi:10.1161/01.HYP.0000124667.34652.1a

20. Campbell DJ, Zeitz CJ, Esler MD, Horowitz JD. Evidence against a major role for angiotensin converting enzymerelated carboxypeptidase (ACE2) in angiotensin peptide metabolism in the human coronary circulation. Jornal of Hypertension 2004; 22(10): 1971-6. doi:10.1097/00004872200410000-00020

21. Ramchand J, Patel SK, Srivastava PM, Farouque O, Burrell LM. Elevated plasma angiotensin converting enzyme 2 activity is an independent predictor of major adverse cardiac events in patients with obstructive coronary artery disease. PLoS One 2018; 13(6). doi:10.1371/journal.pone.0198144

22. Epelman S, Shrestha K, Troughton RW, et al. Soluble Angiotensin-Converting Enzyme 2 in Human Heart Failure: Relation With Myocardial Function and Clinical Outcomes. Journal of Cardiac Failure 2009; 15(7): 565-71. doi:10.1016/ j.cardfail.2009.01.014

23. Soler MJ, Barrios C, Oliva R, Batlle D. Pharmacologic modulation of ACE2 expression. Current Hypertension Reports 2008; 10(5): 410-414. doi:10.1007/s11906-0080076-0

24. Guo J, Huang Z, Lin L, Lv J. Coronavirus Disease 2019 (COVID-19) and Cardiovascular Disease: A Viewpoint on the Potential Influence of Angiotensin-Converting Enzyme Inhibitors/Angiotensin Receptor Blockers on Onset and Severity of Severe Acute Respiratory Syndrome Coronavirus 2 Infection. Journal of the American Heart Association 2020; 9(7): e016219. doi:10.1161/JAHA.120.016219

25. Imai Y, Kuba K, Rao S, et al. Angiotensin-converting enzyme 2 protects from severe acute lung failure. Nature 2005; 436(7047): 112-16. doi:10.1038/nature03712

26. Gurwitz D. Angiotensin receptor blockers as tentative SARSCoV-2 therapeutics. Wiley Online Library 2020. doi:10.1002/ ddr.21656

27. Liu Y, Yang Y, Zhang C, et al. Clinical and biochemical indexes from 2019-nCoV infected patients linked to viral loads and lung injury. Science China Life Sciences 2020; 63(3): 364-74. doi:10.1007/s11427-020-1643-8 
28. Dooley HC, Lee KA, Freidin MB, et al. ACE Inhibitors, ARBs and Other Anti-Hypertensive Drugs and Novel COVID-19: An Association Study from the COVID Symptom Tracker App in 2,215,386 Individuals. https://ssrn.com/abstract= 3583469. Accessed May 12, 2020.

29. Zhang P, Zhu L, Cai J, et al. Association of Inpatient Use of Angiotensin Converting Enzyme Inhibitors and Angiotensin II Receptor Blockers with Mortality Among Patients With Hypertension Hospitalized With COVID-19. Circulation Research. April 2020. doi:10.1161/circresaha.120.317134

30. Li J, Wang X, Chen J, Zhang H, Deng A. Association of Renin-Angiotensin System Inhibitors With Severity or Risk of Death in Patients With Hypertension Hospitalized for Coronavirus Disease 2019 (COVID-19) Infection in Wuhan, China. JAMA Cardiology. April 2020. doi:10.1001/ jamacardio.2020.1624
31. Bean D, Kraljevic Z, Searle T, et al. Treatment with ACEinhibitors is associated with less severe disease with SARSCovid-19 infection in a multi-site UK acute Hospital Trust. medRxiv 2020.04.07.20056788; doi: https://doi.org/10.1101/ 2020.04.07.20056788

32. Zhou F, Yu T, Du R, et al. Clinical course and risk factors for mortality of adult inpatients with COVID-19 in Wuhan, China: a retrospective cohort study. Lancet 2020; 395(10229): 1054-62. doi:10.1016/S0140-6736(20)30566-3

33. HFSA/ACC/AHA StatementAddresses Concerns Re: Using RAAS Antagonists in COVID-19. American College of Cardiology. https://www.acc.org/latest-in-cardiology/ articles/2020/03/17/08/59/hfsa-acc-aha-statementaddresses-concerns-re-using-raas-antagonists-in-covid19. Accessed May 2, 2020. 